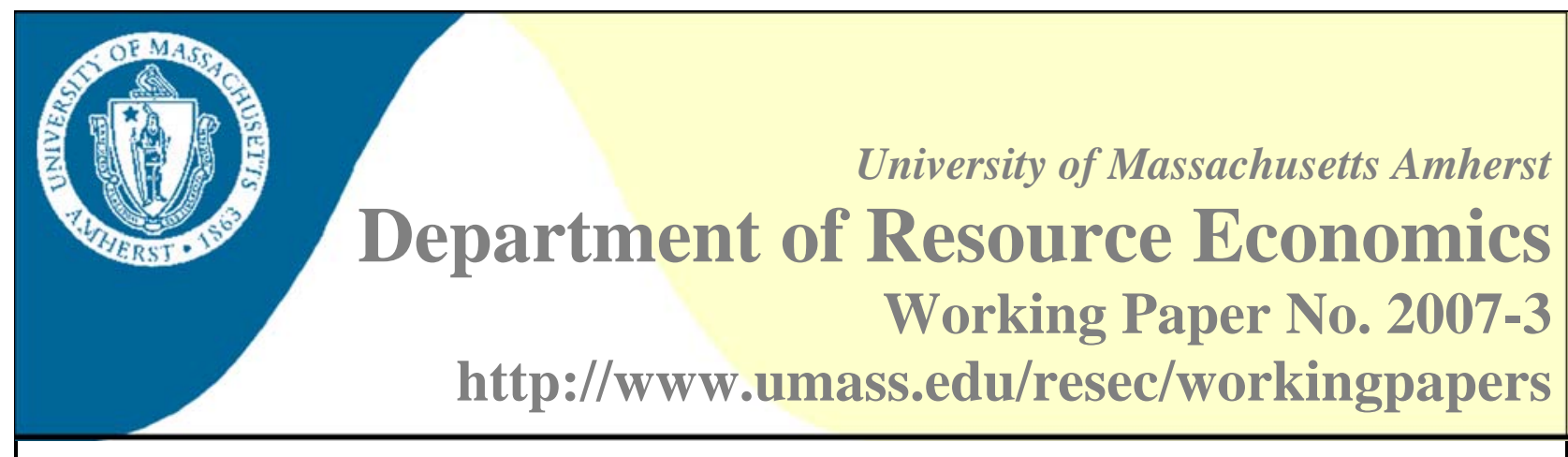

\title{
The Effects of ITQ Management on Fishermen's Welfare When the Processing Sector is Imperfectly Competitive
}

\author{
David M. McEvoy ${ }^{1}$, Sylvia Brandt ${ }^{2}$ and Nathalie Lavoie ${ }^{3}$, and Sven Anders ${ }^{4}$
}

Abstract:

In this paper we use a general model of imperfect competition to predict welfare changes within an open-access fishery transitioning to individual transferable quota (ITQ) management. Although related research has explored the effects of market power in the harvesting sector on ITQ performance, none have considered the implications of an imperfectly competitive processing sector. This study addresses this question specifically in the context of the Atlantic herring fishery, although its implications are relevant to all fisheries with similar industry structure. Our results show that ITQs could have a negative impact on fishermen's welfare when processors have market power and the cap on aggregate harvest is binding or becomes binding with the implementation of ITQs.

Keywords: ITQ, imperfect competition, welfare analysis, fisheries.

JEL Classification: D43, Q22, Q28, L13

\footnotetext{
${ }^{1}$ David M. McEvoy, Department of Resource Economics

University of Massachusetts, Stockbridge Hall

80 Campus Center Way, Amherst, MA 01003

E:dmcevoy@resecon.umass.edu P: 617-671-8147 F: 413-545-5853

${ }^{2}$ Sylvia Brandt, Department of Resource Economics University of Massachusetts, 212G Stockbridge Hall

80 Campus Center Way, Amherst, MA 01003

E: brandt@resecon.umass.edu P: 413-545-5722 F: 413-545-5853

${ }^{3}$ Nathalie Lavoie, Department of Resource Economics

University of Massachusetts, 212D Stockbridge Hall

80 Campus Center Way, Amherst, MA 01003

E: lavoie@resecon.umass.edu P: 413-545-5713 F: 413-545-5853

${ }^{4}$ Sven Anders, Department of Rural Economy

University of Alberta, Edmonton, AB T6G 2H2

E: sven.anders@ualberta.ca P: 780-492-5453 F: 780-492-0268
} 


\title{
The Effects of ITQ Management on Fishermen's Welfare When the Processing Sector is Imperfectly Competitive
}

\author{
David M. McEvoy ${ }^{\mathrm{a}}$, \\ Sylvia Brandt ${ }^{\mathrm{b}}$ and Nathalie Lavoie ${ }^{\mathrm{c}}$, \\ and Sven Anders ${ }^{\mathrm{d}}$ \\ ${ }^{\text {a,b,c }}$ Department of Resource Economics, University of Massachusetts-Amherst, Amherst, MA \\ 01003-9246, USA \\ ${ }^{\mathrm{d}}$ Department of Rural Economy, University of Alberta, Edmonton, AB T6G 2H1, Canada
}

Second authorship is shared equally between Brandt and Lavoie

Acknowledgements: This research was funded by Cooperative Marine Education Research Agreement. The views expressed herein are those of the authors and do not necessarily reflect those of NOAA or any of its subdivisions. We thank Drew Kitz, New England Fisheries Science Center of NMFS, for providing the necessary data and constructive advice. We thank Kohl Kanwit, Maine Department of Marine Resources, and numerous industry representatives for their valuable insights and information on the fishery. The authors are responsible for any remaining errors in the paper.

\footnotetext{
* Please send correspondence to the first author, David M. McEvoy, 80 Campus Center Way, 404 Stockbridge Hall, Amherst, MA 01003, USA, Phone: 617-671-8147, Fax: 413-545-5853, E-mail: dmcevoy@resecon.umass.edu.
} 
Abstract: In this paper we use a general model of imperfect competition to predict welfare changes within an open-access fishery transitioning to individual transferable quota (ITQ) management. Although related research has explored the effects of market power in the harvesting sector on ITQ performance, none have considered the implications of an imperfectly competitive processing sector. This study addresses this question specifically in the context of the Atlantic herring fishery, although its implications are relevant to all fisheries with similar industry structure. Our results show that ITQs could have a negative impact on fishermen's welfare when processors have market power and the cap on aggregate harvest is binding or becomes binding with the implementation of ITQs.

Keywords: ITQ, imperfect competition, welfare analysis

JEL Codes: D43, Q22, Q28, L13. 


\section{Introduction}

Tradeable property rights systems are increasingly being considered by fisheries management as the most promising solution to the problems that often accompany open-access resource use. The potential efficiency gains from tradeable property rights over the more traditional commandand-control style regulations, given all the strict assumptions are satisfied, are well documented in both the theoretical and empirical literature [Moloney and Pearse 1979; Weninger 1998; Grafton, Squires and Fox 2000; Weninger, Grafton, Kirkley and Squires 2003]. By introducing individual transferable quotas (ITQs) into a perfectly competitive fishery in which fishermen have complete information, can interact in the permit market with zero transactions costs, and where the initial distribution of quotas does not affect the marginal valuation of the resource, the fishery is expected to realize an efficient distribution of fishing effort.

In tandem with the predicted efficiency gains, recent research has emphasized that fishermen, in aggregate, may achieve welfare increases as a result of ITQ management [Terrebonne 1995; Matulich and Sever 1999; Heaps 2003; Boyce 2004]. However, these potential welfare gains depend critically on the assumption that all sectors of the fishing industry are perfectly competitive and that consumers' demand is elastic. Case studies of fisheries in which these assumptions do not accurately describe the industry are ubiquitous (for a review see National Research Council 1999).

A number of studies in the economics literature analyze how monopoly power in the harvesting sector (fishermen amassing large percentages of quotas) may alter the environmental and economic performance of ITQs [Anderson 1991; Adelaja, Menzo and McCay 1998]. In contrast, very few studies have analyzed the problem of introducing a property rights system in a fishery with a less than competitive processing sector. In a related study, Matulich, 
Mittelhammer and Reberte (1996) explore the welfare losses to processors with nonmalleable capital investments under an ITQ regime. Their research, however, does not extend the analysis to allow processors to exercise market power in the purchase of input and sale of output. Love (1995) uses data from the Pacific halibut industry to test for the existence of market power in the processing sector. He finds that the degree of monopsony power varies inversely with the length of the fishing season. However, the study does not estimate how market power in the processing sector impacts the welfare levels of the fishery's participants.

This paper contributes to the existing literature by developing a flexible model of imperfect competition for analyzing the long-run effects of ITQ management on fishermen's welfare in the presence of an imperfectly competitive processing sector. The analysis is developed in the context of the Atlantic herring fishery, but may be generalized to any fishery exhibiting similar industry structure.

Predicting how policy-induced welfare measures change when relaxing the assumption of a perfectly competitive industry is critical for analyzing many fisheries as well as multi-tiered agricultural product markets in general [Sexton 2000; McCorriston 2002]. Related agricultural market studies show that the existence of oligopsony-oligopoly power in the processing of foods can affect the size and distribution of welfare changes from technological innovation [Chen and Lent 1992; Dryburgh and Doyle 1995; Huang and Sexton 1996; Alston, Sexton and Zhang 1997; Hamilton and Sunding 1997; Sexton and Zhang 1996]. In general, if regulators falsely assume that an industry is behaving perfectly competitive, the predicted consequences of prescribed policies are likely to be misleading.

The remainder of the paper proceeds as follows: Section 2 provides a background on the management of Atlantic herring and the structure of the bait processing industry; in Section 3 we 
develop the general model; Section 4 presents the welfare analysis; Sections 5 and 6 provide a discussion of policy implications and some concluding remarks.

\section{Background on Atlantic herring}

\subsection{Existing regulation and the need for further action}

The Atlantic herring fishery is on the verge of implementing property rights based management. Since January 2000, the Atlantic herring fishery has been managed under a federal fisheries management plan (FMP) developed jointly by the New England Fisheries Management Council (NEFMC) and the Atlantic States Marine Fisheries Commission (ASMFC). ${ }^{\mathrm{i}}$ The fishery is divided into four management areas (figure 1), and the primary management tool is a cap on aggregate harvest and harvests within each area (the total allowable catch, or TAC) [NEFMC 1999].

[Insert Figure 1 here]

Given that existing regulations do not limit the number of participants allowed in the fishery nor do they limit individual effort levels, in practice the fishery remains open access. Like other fisheries that restrict aggregate harvest levels without restricting effort levels, an unbounded number of fishermen race for an unspecified portion of the herring total allowable catch (TAC). This type of derby fishing promotes inefficiencies and potentially limits the length of the fishing season, which can disrupt herring supplies and jeopardize the overall stability of the fishing industry [Gordon 1954; NEFMC 2005].

In response to these concerns, the two management bodies (NEFMC and ASMFC) have developed the first amendment to the 2000 management plan. The objectives of the amendment 
include to "prevent excess capacity in the harvesting sector" and to "minimize, to the extent practicable, the race to fish for Atlantic herring in all management areas" [NEFMC 2005]. To address these broad goals, there is a provision within the amendment to allow an ITQ system to be implemented in the future through a streamlined public review process. ${ }^{\text {ii }}$

In aggregate, the statistics available on the status of the commercial herring fishery suggest little cause for immediate management action. Total harvests during 2000 to 2004 have averaged roughly only $55 \%$ of the fishery-wide TAC. In addition, scientific assessments indicate that the herring biomass as a whole has been increasing over recent years. ${ }^{\mathrm{iii}}$ However, when analyzing the fishery by individual management areas there are two major causes for concern. First, effort is not dispersed evenly throughout the four management areas of the fishery. The inshore area 1A has rapidly exhausted $100 \%$ of its quota in four of the five years between 2000 and 2004 (table 1). The other inshore area, area 1B, has also witnessed high harvest levels relative to the two offshore management areas. Fishermen and management continue to voice concern about the existing race to fish in management area $1 \mathrm{~A}$ and how those resulting inefficiencies may become exacerbated with any increase in demand for herring.

\section{[Insert Table 1 here]}

The uncertainties surrounding an abrupt increase in the demand for herring motivate the second major concern. Although currently the market supply and demand for herring have settled at a quantity below the TAC, there is evidence that this could change. As the primary source of bait for American lobstermen, the health of the herring fishery, which allocates roughly $60 \%$ of its total harvest to lobster bait, is consequently very dependent on the state of the lobster industry. Lobsters have long remained the most lucrative commercial fishery on the eastern coast of the United States, earning annual revenues averaging over 300 million dollars in the past five years. 
Although lobster harvest rates have remained relatively stable over the same time frame, in 2004 the fishery witnessed the largest annual catch since 1999 (roughly 40,000 metric tons), a 23\% increase from 2003 [NOAA 2006]. In addition, developments in information and shipping technologies have enabled the fishery to meet demands outside of New England. New shipping products like the "Habitat Packing Solution" allow live lobsters to be shipped virtually anywhere in the world at reasonable costs [East Coast Seafood Company 2006].

The primary concern regarding a future swift increase in the demand for herring as lobster bait is that it could exacerbate the already inefficient race to the fish in areas 1A and 1B. The majority of herring sold as lobster bait is harvested from these inshore areas. A positive shock in demand would likely create incentives that could potentially motivate additional participants to enter the industry, thus exacerbating problems associated with excess capacity. ${ }^{\text {iv }}$ Although a portion of the predicted increase in effort could take place in the offshore areas, the added costs of transport and refrigeration tied to harvesting bait in these areas would likely limit such a movement. Thus, further regulatory action to alleviate the problems associated with derby-style fishing is imperative.

\subsection{ITQ management in the Atlantic herring fishery and the concern for market power}

Although an individual property rights system has been submitted under Amendment 1, not all stakeholders are supportive. Processors voice concern about a drastic change in the flow of herring supply due to a change in the fishing season and its effect on their processing capacity. Herring fishermen as well hold a number of apprehensions. Herring fishermen disagree on how and to whom ITQs should be allocated, and many fear manipulation of the ITQs market by those 
with large holdings. Herring fishermen may have yet another reason for remaining skeptical concerning ITQ management and it is this concern that motivates our analysis.

Well over half of the total herring harvest is sold as bait to American lobster fishermen, and in Maine, herring has long remained the preferred bait by lobstermen. The majority of herring processed as bait is channeled through a handful of large wholesalers who then sell to smaller dealers and lobster wharfs [NEFMC 2006]. ${ }^{\vee}$ The four largest wholesalers market $56 \%$ of the herring harvest (table 2) ${ }^{\mathrm{vi}}$ Bait wholesalers have vertically integrated their operations in a number of ways, including producing their own ice, generating their own power, owning trucks and performing maintenance and repairs onsite. Within the largest wholesaler operations, very few components of bait processing are outsourced [NEFMC 2005]. With such a concentrated and vertically integrated bait industry, the potential for wholesalers to exercise market power in the buying of raw herring and the selling of finished bait may potentially alter the predicted benefits of ITQ management.

\section{[Insert Table 2 here]}

Although only aggregate data were available, average industry input and output prices suggest imperfect competition at the processor's level. Based on NEFMC reports, in 2003 the average price paid for raw herring was $\$ .08$ per pound, the lowest price being $\$ .05$ per pound for the month of July and the highest being \$.16 per pound for the month of October [NEFMC 2004]. The average price per pound of barreled bait in the same period (accounting for the weight in salt) is calculated at $\$ .27$ per pound [NEFMC 2005]. It is reasonable to believe the processing costs associated with rinsing, salting, barreling and shipping would likely not explain the $330 \%$ markup. 
Additionally, there is evidence of barriers preventing additional bait processors from entering the industry. First, as with many fisheries, Atlantic herring fishermen have long-lasting, close-knit relationships with their buyers [Acheson 1981; 1985]. Many vessels sell their entire annual harvests exclusively to a single dealer. This relationship instigated the development of the 'days-out' agreement specified in the ASMFC's management plan. The days-out regulation limits the number of days fishing to five per week. The regulation was first implemented and enforced cooperatively by both fishermen and buyers to extend the fishing season to insure stability of both the lobster and herring fishery. Over time the regulation has been codified into the states' management plan but is still monitored and enforced informally by both sectors of the industry. This strong long-term relationship can prevent outsiders from seamlessly entering and establishing clientele in the bait processing sector. An additional hindrance to entry is the physical constraint of having only a limited number of fishing ports and associated space to build a processing plant. From 2000 to 2004 , an average of $56 \%$ of total herring harvests have been landed at the same three ports [NEFMC 2006]. These barriers, along with the evidence of a concentrated processing sector earning significant price markups, are suggestive of the existence of imperfect competition among bait dealers.

In the next section we present a model of a fishery consisting of bait buyers, bait processors and fishermen selling fish to be processed as bait. The model will then be used in section 4 to examine the welfare effects of implementing an ITQ system when bait processors have market power. 


\section{The model}

Consider a fishing industry comprised of three distinct sectors: herring fishermen, bait processors who act as middlemen in the purchase of raw herring and sale of herring bait, and lobstermen who are the final bait consumers. The single existing regulation in the fishery is a cap on aggregate harvest.

There are $F$ heterogeneous fishermen $j=(1,2, \ldots, F)$ in the industry each harvesting a homogeneous fish product. Fishermen are assumed to behave perfectly competitively taking input prices and output prices as given. Fishermen choose their level of fishing effort to maximize

$$
\pi_{j}=f\left(b_{j}\left(e_{j}\right), W, c\left(e_{j}\right)\right),
$$

where $\pi_{j}$ is individual profit, $b_{j}\left(e_{j}\right)$ is the harvesting production function determining the quantity of raw fish supplied to the bait dealers as a function of effort, $e_{j}$ is individual effort level (e.g., days fishing), $W$ is the unit price paid to fishermen for their harvest, and $c$ is the variable cost of fishing as a function of an individual's effort. We assume concavity of the production function and convexity of the cost function which requires $b_{j}^{\prime}\left(e_{j}\right)>0, b_{j}^{\prime \prime}\left(e_{j}\right)<0$, $c^{\prime}\left(e_{j}\right)>0$, and $c^{\prime \prime}\left(e_{j}\right)>0$. Solving the first-order condition for the optimal level of effort $e_{i}^{*}(W)$ and substituting this term into the harvesting production function yields a representative fisherman's supply curve, $b_{j}\left(e^{*}(W)\right)$.

The market supply schedule for raw fish (denoted by $B$ ) is a simple aggregation of the individual supply functions of the fishermen 


$$
\sum_{j=1}^{F} b_{j}\left(e^{*}(W)\right)=B\left(e^{*}(W)\right)=B(W)
$$

subject to the constraint that market supply can not surpass the total allowable catch $B(W) \leq T A C$.

On the other side of the market, $L$ perfectly competitive lobster fishermen $(l=1,2, \ldots, L)$ purchase bait as an input into their production of lobster. Each is assumed to maximize

$$
\pi_{l}=f\left(k_{l}\left(q_{l}\right), P, R\right)
$$

where $\pi_{l}$ is individual profit, $k_{l}\left(q_{l}\right)$ is the quantity of lobster sold as a function of the quantity of bait purchased as an input, $P$ is the unit price of bait and $R$ is the output price of lobster. Cost elements other than the price of bait have been excluded from the profit function without loss of generality. Solving the first-order condition for the optimal quantity of bait yields an individual lobsterman's demand function for bait, which, when aggregated, forms the market demand function

$$
\sum_{l=1}^{L} q_{l}(P, R)=Q(P, R) .
$$

The middlemen sector consists of $M$ processors $(m=1,2, \ldots, M)$ transforming a single input raw herring $(b)$ - into a homogeneous output - herring bait $(q){ }^{\text {vii }}$ The production function for bait output is characterized by fixed proportions between the raw input and the final output, i.e., $q_{m}=\alpha b_{m}$. More specifically, we assume that raw herring is transformed into bait in a one-to-one relationship, i.e., $\alpha=1$. This assumption is reasonable considering that the process of transforming raw fish to bait does not produce significant quantities of wasted harvest. The profit function of a representative bait processor $m$ is expressed as 


$$
\pi_{m}=P(Q(P, R)) q_{m}-W(B) b_{m}-C\left(q_{m}\right)
$$

where $C$ is the processing cost of bait and $q_{m}$ and $b_{m}$ are the quantities of bait sold and raw herring purchased, respectively. With fixed proportions, equation [5] shows that the cost function of the processor is separable into input costs and processing costs. Assuming further that there are constant returns to scale in processing, then $C\left(q_{m}\right)=c q_{m}$, where $c$ is the marginal processing cost and is a function of the price of processing inputs. Thus, the first-order condition of the profit-maximization problem is

$$
\frac{\partial \pi_{m}}{\partial b_{m}}=0 \rightarrow\left[P(Q)+P^{\prime}(Q) \frac{\partial Q}{\partial q_{m}} q_{m}-C\right]=W(B)+W^{\prime}(B) \frac{\partial B}{\partial b_{m}} b_{m} .
$$

This expression states that profit is maximized at the quantity where the representative processor equates the marginal revenue from selling an additional unit of output, less the marginal processing cost, to the marginal outlay from purchasing an additional unit of input. The expression can be re-written as

$$
\left[P(Q)\left(1+\frac{\theta_{m}}{\varepsilon}\right)-C\right]=W(B)\left(1+\frac{\lambda_{m}}{\eta}\right)
$$

where $\varepsilon=(\partial Q / \partial P)(P / Q)$ is the market price elasticity of demand for bait and $\eta=(\partial B / \partial W)(W / B)$ is the market price elasticity of supply for raw herring. The terms $\theta_{m}=\left(\partial Q / \partial q_{m}\right)\left(q_{m} / Q\right)$ and $\lambda_{m}=\left(\partial B / \partial b_{m}\right)\left(b_{m} / B\right)$ are the processors' conjectural variations in elasticity form for the final product and the raw input respectively.

Because we assume bait processors produce homogeneous products and have identical production technologies, optimization requires that each firm's conjectural variation be identical, i.e., $\theta_{1}=\theta_{2}=\ldots=\theta$ and $\lambda_{1}=\lambda_{2}=\ldots=\lambda$. Therefore, the industry equilibrium condition is: 


$$
\left[P(Q)\left(1+\frac{\theta}{\varepsilon}\right)-C\right]=W(B)\left(1+\frac{\lambda}{\eta}\right)
$$

which in conjunction with the market supply equation [2] and the market demand equation [4] yields equilibrium values for $P, W$ and $Q=B$ for any given set of parameters.

\section{Welfare analysis}

In this section we compare predicted changes in fishermen's surplus when transitioning from open-access to individual property rights management. By allowing for varying degrees of processors' imperfectly competitive behavior, we compare how ITQ management affects fishermen's welfare. The one regulation in common between the open-access and ITQ management is the existence of an exogenously determined TAC. Under ITQs fishermen are guaranteed a portion of the established TAC through their quotas. Fishermen will buy or sell quota until each equates its marginal benefit from fishing to the market price for the ITQ [National Research Council 1999; Grafton, Kirkley, Squires and Weninger 2000; Grafton, Squires and Fox 2000; Weninger 2002]. Thus, in contrast to the overinvestment in capital, production inefficiencies, and overcrowding externalities resulting from open-access management, the long-run equilibrium under ITQs satisfies the condition for an efficient allocation of the resource [Matulich, Mittelhammer and Reberte 1996]. Furthermore, the literature on ITQs predicts a reduction in capital and marginal fishing costs as the less efficient vessels exit the fishery [Weninger 2002; Squires 2003]. We use these results from the literature to simulate the market effects of ITQ management; therefore, the welfare analysis pertains to harvesters active in the long run and does not consider welfare changes during the transition to ITQs. 
The ITQ-induced reduction in marginal fishing cost is captured in our model by an outward pivot (decrease in slope) of the market supply curve for raw fish, and is consistent with similar supply analyses by Dryburgh and Doyle (1995) and Alston, Sexton and Zhang (1997). To proceed with the welfare analysis, we characterize the fishery following the expressions for market supply and demand introduced by Huang and Sexton (1996) and Homans and Wilen (2005). Specifically, we denote

$$
B=\beta W^{\eta},
$$

and

$$
Q=\delta P^{-\varepsilon},
$$

as the market supply [2] and market demand [4] for herring, respectively. In these expressions, $B$ is the quantity of raw fish supplied, $\beta$ is a positive parameter, $W$ is the input price of raw fish, $Q$ is the quantity of bait demanded, $\delta$ is a positive parameter, $P$ is the output price of bait and $\eta$ and $\varepsilon$ are the price elasticities of supply and demand, respectively. These general functional forms satisfy the established property that welfare changes depend most critically on the price elasticities of supply and demand (Alston, Sexton and Zhang 1997).

We consider three situations that likely reflect the varying circumstances in each of the four management areas in the herring fishery: (1) the TAC is nonbinding under open-access and remains nonbinding with ITQs (e.g., area 2 and area 3), (2) the TAC is binding under open-access and remains binding with ITQs (e.g., area 1A), and (3) the TAC is nonbinding under open-access but becomes binding once ITQs are introduced (e.g., area 1B). The implicit assumption when categorizing areas according to the TAC is that fishermen do not move between areas. This feature is consistent with the ITQ system proposed by herring management which allocates quotas tied to specific fishing areas. Trade between management areas must be restricted because 
each area has different characteristics (e.g., stock assessments, number of participants and preexisting gear and effort restrictions) that require different management strategies.

\subsection{Nonbinding TAC}

In this section we assume fishermen are consistently harvesting under their area's TAC and harvest is free to increase or decrease according to the specific management policy (open-access or ITQs). This initial scenario corresponds to the conditions in the off-shore fishing areas 2 and 3 in which annual harvest remains significantly below their respective quotas.

\subsubsection{Perfect competition}

The baseline case to consider is that of open-access management under a perfectly competitive processing sector. Equilibrium quantities are therefore determined by substituting [2a], [4a] and $\theta, \lambda=0$ into [8] and solving for $Q_{o a}=B_{o a}$ where the subscript oa indicates quantities under

open-access management. This equilibrium is illustrated in figure $2 .^{\text {viii }}$ In this and other figures, it is the herring market that is depicted, thus the demand is the derived demand of the processor for herring. To depict the market at the bait level, both supply and derived demand would shift up by the constant marginal processing cost, $c$. The equilibrium prices of herring and bait (net of the marginal processing cost) are found at the intersection of the derived demand and supply curves, i.e., $P_{o a}=P\left(Q_{o a}\right), W_{o a}=W\left(B_{o a}\right)$, and $P_{o a}=W_{o a}$.

[Insert Figure 2 here]

Our analysis is focused exclusively on producer (fishermen) surplus and therefore we do not compute changes in consumer's (lobstermen's) welfare. ${ }^{\text {ix }}$ Producer surplus under open-access management is represented by area $A B_{o a} W_{o a}$ in figure 2 and is expressed as 


$$
P S_{o a}=W_{o a} B_{o a}-\int_{0}^{B_{o a}} W(B) d B=\frac{\left(\beta^{(\varepsilon-1)} \delta^{(\eta+1)}\right)^{1 /(\eta+\varepsilon)}}{(\eta+1)}
$$

Recall, we capture the reduction in marginal fishing cost due to ITQ management as an outward pivot in supply. The new market supply function under ITQ management is

$$
B=\beta(W z)^{\eta}
$$

where $z$ is a positive parameter greater than $1 .^{\mathrm{x}}$ Solving for $W$ yields the new inverse supply function $\hat{W}=(1 / z)(B / \beta)^{1 / \eta}$. Because the TAC is not binding, meaning prices and quantities are free to change, the equilibrium net prices and quantities are determined by substituting [2b], [4a] and $\theta, \lambda=0$ into [8] and solving for $Q_{I T Q}=B_{I T Q}$ where the subscript ITQ indicates ITQ management under perfect competition. The equilibrium prices of herring and bait (net of marginal processing cost) are found at the intersection of the derived demand and supply curve, i.e., $P_{I T Q}=P\left(Q_{I T Q}\right), W_{\text {ITQ }}=W\left(B_{\text {ITQ }}\right)$ and $P_{I T Q}=W_{\text {ITQ }}$ (figure 2). Producer surplus in this case is represented by area $A B_{1} W_{\text {ITQ }}$ in figure 2 and is expressed as

$$
\begin{aligned}
& P S_{\text {ITQ }}=W_{\text {ITQ }} B_{\text {ITQ }}-\int_{0}^{B_{\text {ITQ }}} \hat{W}(B) d B= \frac{\left(z^{\eta(\varepsilon-1)} \beta^{(\varepsilon-1)} \delta^{(\eta+1)}\right)^{1 /(\eta+\varepsilon)}}{(\eta+1)} \\
&=Z^{\frac{\eta(\varepsilon-1)}{(\eta+\varepsilon)}} P S_{o a} .
\end{aligned}
$$

The gain in producer surplus caused by an outward pivot in the market supply curve is the area $A B_{1} C$ while the corresponding loss in surplus is the area $W_{\text {ITQ }} C B_{0} W_{\text {oa }}$. The change in producer surplus due to the introduction of property rights management, is expressed formally as 


$$
\Delta P S=P S_{I T Q}-P S_{o a}=P S_{o a}\left(z^{\frac{\eta(\varepsilon-1)}{\varepsilon+\eta}}-1\right)
$$

Given that $z>1$, the change in producer surplus under perfect competition will be strictly greater than zero if demand for bait is elastic $(\varepsilon>1)$. Thus, under an elastic demand for bait, there is an increase in welfare for fishermen from a transition from open-access to ITQ management. In this case, the gain in producer surplus from an increase in quantity sold will more than offset the simultaneous loss in surplus from the lower price. However, if the demand for bait is inelastic $(\varepsilon<1)$, the change in surplus will be strictly less than zero, which translates to a decrease in welfare from the change in management. Finally, if the price elasticity of demand is exactly one, there will be no change in surplus from the adoption of ITQs. This result is consistent with previous studies which show that if demand is inelastic and markets are competitive, producers will necessarily lose from a proportional supply shift [Alston, Sexton and Zhang 1997].

\subsubsection{Imperfect competition}

We now relax the assumption of a perfectly competitive processing sector and allow the conjectural variation parameters to take on positive values, i.e., $\theta, \lambda \in(0,1)$. The herring harvesters and the lobstermen as final bait consumers are assumed to remain perfectly competitive. Equilibrium prices and quantities are now determined by substituting [2a], [4a] into [8] and solving for $Q_{\text {ioa }}=B_{\text {ioa }}$ where the subscript ioa indicates open-access prices and quantities in the presence of an imperfectly competitive processing sector. The equilibrium prices for herring and bait (net of marginal processing cost) are found on the respective supply and derived demand curves at the equilibrium quantity, i.e., $P_{\text {ioa }}=P\left(Q_{\text {ioa }}\right)$ and $W_{\text {ioa }}=W\left(B_{\text {ioa }}\right)$ (figure 3 ). 


\section{[Insert Figure 3 here]}

Producer surplus in this case is represented by area $A B_{0} W_{\text {ioa }}$ in figure 3 and is expressed as

$$
P S_{\text {ioa }}=W_{\text {ioa }} B_{\text {ioa }}-\int_{0}^{B_{\text {ioa }}} W(B) d B=\frac{\left(\beta^{(\varepsilon-1)} \delta^{(\eta+1)}\right)^{1 /(\eta+\varepsilon)}}{\eta+1}\left[\frac{(\varepsilon-\lambda)}{\varepsilon} \frac{\eta}{(\eta+\theta)}\right]^{\varepsilon(\eta+1) /(\eta+\varepsilon)} .
$$

We proceed, as before, by assuming the long-run impact of ITQ management is captured by an outward pivot of the market supply curve. With a pivot in supply, the equilibrium prices and quantity are found by substituting [2b], [4a] into [8] and solving for $Q_{i I T Q}=B_{\text {IITQ }}($ figure 3 ), where the subscript $i T T Q$ denotes ITQ management under imperfect competition. The equilibrium net price for raw herring and bait are found on the respective supply and derived demand curves at the equilibrium quantity, i.e., $P_{\text {iITQ }}=P\left(Q_{\text {iITQ }}\right)$ and $W_{\text {iITQ }}=\hat{W}\left(B_{\text {iITQ }}\right)$. Producer surplus in this case is represented by area $A B_{1} W_{\text {iITQ }}$ in figure 3 and is expressed as

$$
\begin{aligned}
P S_{\text {iITQ }}=W_{\text {iाTQ }} B_{\text {iITQ }}-\int_{0}^{B_{\text {iTT }}} W(B) \mathrm{d} B & =\frac{\left(z^{\eta(\varepsilon-1)} \beta^{(\varepsilon-1)} \delta^{(\eta+1)}\right)^{1 /(\eta+\varepsilon)}}{\eta+1}\left[\frac{(\varepsilon-\lambda)}{\varepsilon} \frac{\eta}{(\eta+\theta)}\right]^{\varepsilon(\eta+1) /(\eta+\varepsilon)} \\
& =z^{\frac{\eta(\varepsilon-1)}{\eta+\varepsilon}} P S_{\text {ioa }} .
\end{aligned}
$$

In figure 3, the gain and loss in producer surplus from an ITQ-driven outward pivot in market supply is illustrated by areas $A C B_{1}$ and $W_{\text {ioa }} B_{0} C W_{\text {iITQ }}$, respectively. The change in fishermen's surplus corresponds to

$$
\Delta P S_{i}=P S_{\text {iITQ }}-P S_{\text {ioa }}=P S_{\text {ioa }}\left(z^{\frac{\eta(\varepsilon-1)}{\varepsilon+\eta}}-1\right) .
$$

The expression above (the subscript $i$ indicates imperfect competition) indicates that producers will lose from ITQ management if demand is inelastic $(\triangle P S<0)$, but gain if demand is elastic 
$(\triangle P S>0)$. Moreover, the magnitude of the gain or loss in producer surplus following the implementation of ITQs depends on the size of the pivotal shift and the elasticity of demand and supply. Contrary to the perfectly competitive scenario, $P S_{\text {ioa }}$ depends on the level of market power of the processors in both the purchase of herring and sale of bait, i.e., it depends on $\lambda$ and $\theta$. More specifically, the size of the gain/loss in producer surplus from ITQs decreases with the increase in the level of market power of processors.

In summary, regardless of processor behavior, when the TAC is nonbinding, herring fishermen necessarily gain from ITQs if the demand for bait is elastic (table 3). However, if processors have market power in herring purchase and/or bait sale, the magnitude of the gains from ITQs will decrease with an increase in market power.

\subsection{Binding TAC}

In the previous section we assumed fishermen were consistently harvesting less than their area's TAC. To address the circumstances within the inshore fishing area $1 \mathrm{~A}$ in which the TAC is consistently exhausted, we now assume the TAC will be binding under both management options.

\subsubsection{Perfect competition}

The TAC is assumed to be set somewhere between zero and the equilibrium quantity that would be realized in the absence of a quantity restriction, i.e., $B_{T A C} \in\left[0, B_{o a}\right]$. Under the binding quota assumption, along with $\theta, \lambda=0$, the equilibrium prices are determined by substituting $B_{T A C}$ into [2a] and [4a]. In other words, the price of herring is determined at the intersection of derived demand and supply where the supply becomes vertical at the TAC level (figure 4). 


\section{[Insert Figure 4 here]}

The corresponding producer surplus is represented by area $A B_{0} P_{T A C}$ in figure 4 and is expressed as

$$
P S_{o a}=W_{T A C} B_{T A C}-\int_{0}^{B_{T A C}} W(B) d B=\left(\delta B_{T A C}^{\varepsilon-1}\right)^{1 / \varepsilon}-\frac{\eta}{1+\eta}\left(\frac{B_{T A C}^{\eta+1}}{\beta}\right)^{1 / \eta} .
$$

With the imposition of ITQs we expect, as before, an outward pivot in the market supply curve captured by $[2 \mathrm{~b}]$. However, now the aggregate harvest level is fixed at $B_{T A C}$. Thus, fishermen sell the same quantity of herring for the same net price $W_{T A C}$, but producer surplus has increased due to the increase in efficiency associated with ITQs. Producer surplus under ITQ management is represented by area $A B_{1} B_{0} W_{T A C}$ and is expressed as

$$
P S_{I T Q}=W_{T A C} B_{T A C}-\int_{0}^{B_{\mathrm{TAC}}} \hat{W}(B) d B=\left(\delta B_{T A C}^{\varepsilon-1}\right)^{\frac{1}{\varepsilon}}-\frac{1}{Z} \frac{\eta}{1+\eta}\left(\frac{B_{T A C}^{\eta+1}}{\beta}\right)^{\frac{1}{\eta}} .
$$

In figure 4, area $A B_{1} B_{0}$ represents the gain in producer surplus from an ITQ-driven outward pivot in market supply. The change in producer surplus can be expressed formally as

$$
\Delta P S=P S_{I T Q}-P S_{o a}=\frac{\eta}{1+\eta}\left(\frac{B_{T A C}^{\eta+1}}{\beta}\right)^{\frac{1}{\eta}}\left(1-\frac{1}{z}\right)
$$

Recall that $z>1$, and therefore the change in producer surplus must be positive. Thus fishermen will strictly gain from the imposition of ITQs when the industry is perfectly competitive and the TAC is binding.

\subsubsection{Imperfect competition}

The binding level of harvest when allowing for imperfect competition among processors is similarly expressed as $B_{i T A C} \in\left[0, B_{i o a}\right]$, i.e., the TAC is set somewhere between zero and the 
unregulated equilibrium. As before, the equilibrium output price for herring is determined where the fixed supply, $B_{i T A C}$, intersects the derived demand curve for bait, i.e., $P\left(B_{\text {ITAC }}\right)$. As Sexton and Zhang (1996) point out, with an inelastic supply curve, the traditional industrial organization models to determine equilibrium prices under imperfect competition are not valid. Following Sexton and Zhang, with a binding quota on harvest, the division of fixed surplus between the processors and herring fishermen is essentially a bargaining problem. For our welfare analysis, the price paid to fishermen for raw bait is set somewhere between the perfectly competitive price, $P\left(B_{\text {ITAC }}\right)$, and the price realized under a monopsonist processor, $W\left(B_{\text {ITAC }}\right)$. The exact input price is assumed to be a decreasing function of the level of market power of the processors in purchase of herring, i.e., a function of oligopsony power as measured by $\lambda \in(0,1)$. The rational is that when there are more firms (i.e., less market power and a smaller $\lambda$ ), firms will bid against one another, increasing the price of the input. As market power decreases, through an increase in the number of buyers of raw herring for example, the price paid to fishermen moves closer to the price under perfect competition.

Using $\lambda$ as our proxy for the level of processor bargaining power in setting the price of raw herring, the open-access equilibrium net input price is $W_{\text {iTAC }}=\lambda W\left(B_{\text {ITAC }}\right)+(1-\lambda) P\left(B_{\text {iTAC }}\right)$. The price of herring $W_{\text {ITAC }}$ is therefore a weighted average of the price realized under perfect competition $(\lambda=0)$ and the price that would exist under a single bait processor or a perfectly collusive group of processors $(\lambda=1)$.

The price of the bait output (net of marginal processing cost) is found on the derived demand curve at the quota quantity, i.e., the price of the output is $P\left(B_{\text {ITAC }}\right)$. Figure 5 illustrates 
the equilibrium for the special case where $\lambda=1$. The producer surplus is represented by area $A D W_{\text {iTAC }}$ and is expressed generally as

$$
P S_{\text {ioa }}=\left[\lambda W\left(B_{\text {iTAC }}\right)+(1-\lambda) P\left(B_{\text {iTAC }}\right)\right] B_{\text {iTAC }}-\int_{0}^{B_{i T A C}} W(B) d B
$$

[Insert Figure 5 here]

An outward pivot in the supply curve, in the absence of a quantity restraint, would motivate the imperfectly competitive processing sector to demand an increase in the amount of herring it purchases and sells on the market (figure 5). However, because the TAC is assumed binding, the rotation in the supply curve caused by the implementation of ITQs simply decreases the price processors with market power have to pay fishermen for the same quantity of herring and thus increases the processors' markup. Under these conditions, the new producer surplus is represented by area $A B W_{\text {iITQ }}$ in figure 5 and is expressed generally as

$$
P S_{i I T Q}=\left[\lambda \hat{W}\left(B_{i T A C}\right)+(1-\lambda) P\left(B_{i T A C}\right)\right] B_{i T A C}-\int_{0}^{B_{i T A C}} \hat{W}(B) d B
$$

and the corresponding change in producer surplus is

$$
\Delta P S_{i}=P S_{\text {iITQ }}-P S_{\text {iоa }}=\frac{B_{i T A C}^{(\eta+1) / \eta}}{\beta^{1 / \eta}}\left(\frac{1}{z}-1\right)\left(\lambda-\frac{\eta}{\eta+1}\right) .
$$

$\operatorname{Because}(1 / z-1)<0$, equation [20] indicates that fishermen will strictly lose under ITQs if $\lambda>\eta /(\eta+1)$ and will strictly gain when $\lambda<\eta /(\eta+1)$. The change in welfare when $\lambda=1$ is illustrated as area $A C B$ minus area $W_{\text {iITQ }} C D W_{\text {iTAC }}$ in figure 5.

Therefore, when the TAC is binding under open-access management, fishermen are expected to gain from ITQ management if processors are perfectly competitive and lose if processors act as a perfectly collusive monopsony $(\lambda=1)$. When processors are oligopsonists 
$(\lambda \in[0,1])$, the more inelastic is the supply function of herring and the greater the level of market power, the more likely fishermen will lose from the implementation of ITQs. The size of the welfare loss is expected to decrease monotonically with reductions in the level of processor market power, eventually turning to zero once $\lambda=\eta /(\eta+1)$.

Assuming that processors behave as Cournot rivals, the conjectural variation parameter $\lambda$ can be defined as $1 / M$, where $M$ is the number of identical processors. Therefore, for fishermen to lose from ITQ management, $1 / M>\eta /(\eta+1)$ must be satisfied. Rearranging this expression to $\eta<1 /(M-1)$ indicates that the price elasticity of supply must be less than 1/(M-1) for fishermen to lose from ITQ management. For example, with four processors (i.e., $M=4$ ), $\eta$ must be lower than $1 / 3$ for fishermen to suffer a loss. In short, under a rather inelastic supply and a nontrivial level of market power, ITQs are welfare reducing for herring harvesters.

In summary, when the TAC is binding, herring fishermen's welfare improves with the implementation of ITQ if processors are perfectly competitive. However, if processors have market power in the purchase of herring, fishermen could lose from ITQ if market power is significant and/or the elasticity of supply of herring is sufficiently small. These results are summarized in table 3 .

\subsection{Initially nonbinding, and then binding TAC}

In this third and final scenario the TAC is initially assumed not to bind under open-access management but later becomes binding once the ITQ-induced outward pivot in supply occurs. This set of circumstances best reflects fishing effort within the inshore area $1 \mathrm{~B}$ where harvest levels have fluctuated above and below the TAC between 2000 and 2004. Additionally, this 
scenario reflects what stakeholders predict would happen within the off-shore areas if future demand for lobster bait increases.

\subsubsection{Perfect competition}

If all sectors of the fishing industry behave perfectly competitively, the change in fishermen's surplus can be determined by comparing producer surplus under ITQ management with a binding quota [16] and producer surplus under open-access management when the quota is initially nonbinding [9]. Our results for this scenario are summarized in the following proposition.

Proposition 1: With a perfectly competitive fishing industry and a TAC that becomes binding after the imposition of ITQs, an elastic demand $(\varepsilon>1)$ is a sufficient but not a necessary condition for an improvement in fishermen's welfare.

Proof: see appendix A.1

If demand is elastic $(\varepsilon>1)$ fishermen will necessarily gain surplus from individual property rights management. On the other hand, if demand is inelastic, fishermen may gain or lose surplus depending on the interaction of the remaining market parameters. The relationship between the directional change in fishermen's welfare and the remaining market parameters when demand is inelastic $(\varepsilon<1)$ is described in the following Lemma. 
Lemma 1: With a perfectly competitive fishing industry and a TAC that becomes binding after the imposition of ITQs, if demand is inelastic $(\varepsilon<1)$ there is an increase (decrease) in fishermen's welfare when the efficiency gains from ITQ are sufficiently large (small).

Lemma 1 is demonstrated in appendix A.2

If demand is inelastic, fishermen will be increasingly better off as the cost of harvesting declines - the change in producer surplus eventually turning positive for large enough gain in efficiency. Therefore, when demand is inelastic, large decreases in harvesting costs eventually more than offset the decrease in price associated with the increase in quantity to meet the TAC.

\subsubsection{Imperfect competition}

With an imperfectly competitive processing sector, the change in fishermen's welfare is determined by comparing producer surplus with ITQs under a binding quota [19] and the openaccess level of producer surplus with a nonbinding quota [12]. Our results for this scenario are summarized in the following proposition.

Proposition 2: When the processing sector is imperfectly competitive and the TAC becomes binding after ITQ management, $\lambda<\eta /(\eta+1)$ is a sufficient but not a necessary condition for an improvement in fishermen's welfare.

Proof: see appendix A.3

Proposition 2 indicates that fishermen can expect to gain from ITQ management if the processing sector has a limited amount of market power in the purchase of raw herring. Recall 
that $\lambda<\eta /(\eta+1)$ is the condition required for fishermen to benefit from ITQs when the TAC is assumed to be initially binding (see equation [20]). Intuitively, this condition illustrates that if processors have limited bargaining power in setting the price paid to fishermen for raw fish (i.e., low $\lambda$ ), fishermen will gain from the decreased harvesting costs realized through ITQ management.

In circumstances in which $\lambda>\eta /(\eta+1)$, determining whether fishermen gain or lose from ITQs depends on the size of the efficiency gains from ITQ management. This relationship is described in our second lemma.

Lemma 2: When the processing sector is imperfectly competitive and the TAC becomes binding after ITQ management, if $\lambda>\eta /(\eta+1)$, fishermen suffer an increase (decrease) in welfare when $z$ is sufficiently small (large).

Demonstrated in appendix A.4

The intuition behind lemma 2 is that if processors have a significant level of market power when setting the input price, fishermen will be increasingly worse off as the cost of harvesting declines. That is, processors can exploit the low cost of fishing by offering a lower input price. The results from this section are summarized in table 3.

\section{Discussion and policy implications}

Individual property rights management is often proposed as the 'silver bullet' to solving fisheries management problems. The literature on ITQs suggests two reasons for efficiency gains. First, fishermen with relatively high fishing costs will opt to sell their quotas and exit the fishery while 
the remaining participants, in turn, are able to fish the entire TAC at a lower variable cost. Second, because fishermen are guaranteed a fixed portion of the TAC, they no longer have an incentive to race to catch as many fish as quickly as possible allowing each to fish at their own profit-maximizing level of effort. In addition to these efficiency gains, a number of stylized models of ITQ management predict that fishermen, as a whole, will witness an increase in welfare resulting from the management change [Terrebonne 1995]. However, these efficiency and welfare gains have been derived relying on the assumption of a perfectly competitive industry. In many fisheries, and in particular the Atlantic herring fishery, certain sectors of the industry show evidence of imperfectly competitive behavior. Therefore an important question remains concerning the impact of middlemen's market power on fishermen's welfare.

This paper specifically addressed how fishermen's welfare changes in the long run after transitioning from open access to ITQ management in the presence of an imperfectly competitive processing sector. Currently, the level of data available pertaining to the herring fishery does not allow for direct estimation of the degree of processor market power. Atlantic herring management, at this point, only records individual level data on harvest quantities and effort levels (e.g., days fishing, vessel size and number of crew members) for the purposes of managing the TAC. They do not record data on the input and output prices needed for economic analysis. In light of this, we presented a series of empirical observations suggesting the presence and importance of market power at the processing level.

In the herring fishery, effort is unevenly dispersed across four management areas. We considered three scenarios that reflected each of these circumstances: a binding TAC, a nonbinding TAC and a change from nonbinding to binding TAC. Our results show that fishermen may gain or lose welfare depending on the area they fish in, the interaction of the price 
elasticities of supply and demand, and the size of the efficiency gains. In the larger, off-shore fishing areas (areas 2 and 3), where the TAC is not binding, fishermen's welfare is expected to increase, independent of the assumption on processor competitiveness, provided that the demand for bait is elastic. There is enough evidence that although herring are preferred, lobster fishermen have available substitutes for herring as lobster bait (e.g. skate, redfish/flatfish, cunner, menhaden and artificial soy-based products) and therefore the assumption of an elastic demand curve seems reasonable. The implication is that the collection of fishermen in the offshore areas is expected to gain from ITQ management.

Within the popular inshore area $1 \mathrm{~A}$ (where the TAC is already binding), our results indicate fishermen can expect to gain if processors are sufficiently competitive but will necessarily lose if processors exhibit strong degrees of market power in the purchase of raw herring. The magnitude of the loss is directly related to the degree of market power and the size of the efficiency gain, and inversely related to the elasticity of supply. Because the majority of participants currently fish in this area, the possibility of a welfare loss should be factored in as a potential cost to ITQ management.

Finally, in the inshore area 1B within which harvest levels are expected to reach the TAC once ITQs are implemented, we expect fishermen to gain if processors behave competitively and demand is elastic. On the other hand, if processors hold a significant level of market power and/or the efficiency gains from ITQs are relatively low, fishermen in this area are expected to suffer losses from the change in management. 


\section{Conclusion}

While much of the economic literature on ITQs focuses on gains in the aggregate, the fundamental policy debate revolves around the distribution of these gains among industry participants. In this paper we use a general model of imperfect competition to predict changes in fishermen's welfare within an open-access fishery after it transitions to individual transferable quota (ITQ) management. Although the circumstances in the Atlantic herring fishery motivated this analysis, its implications are relevant to all fisheries with similar market characteristics. Contrary to the presumption that efficiency gains benefit all fishermen, our results show that even under perfect competition, whether fishermen benefit from ITQ depends not only on the elasticity of demand and supply, but also on the magnitude of the efficiency gains and on whether the cap on total harvest is binding. In addition, when market power is present, the size of producer welfare gains from ITQs are inversely related to the level of processor market power. Implementing ITQs can even result in a loss in fishermen's welfare under significant levels of market power and, in the case where the TAC becomes binding, under large efficiency gains from ITQs. The overarching implication of this analysis is that fishermen may not witness the predicted welfare gains from ITQ management when processors are capable of capturing some or all of the policy-induced gains in efficiency.

There are four critical implications for renewable resource management that stem from this research. First, evaluations of ITQs need to incorporate the processing sector and explicitly consider market imperfections. Second, if achieving welfare gains for fishermen is a fundamental management objective, relying on a policy of individual property rights is unlikely to generate the desired outcome under the presence of powerful market intermediaries. Third, changes in efficiency of production are not a sufficient measure of gains from ITQs. Last, data needed to 
estimate market power are consistently unavailable for fisheries; however, the critical role of market power on the welfare impacts of ITQs suggests that regulatory agencies should invest in collecting these data. 


\section{References}

Acheson, James M., 1985. "The Main Lobster Market: Between Market and Hierarchy.” Journal of Law, Economics and Organization. 1(2), 385-398.

Acheson, James M., 1981. “Anthropology of Fishing.” Annual Review of Anthropology. 10(1), 275-316.

Adelaja, Adesoji; Menzo, Julia and Bonnie McCay, 1998. "Market Power, Industrial Organization and Tradeable Quotas." Review of Industrial Organization 13(5), 589-601.

Alston, Julian M.; Sexton, Richard J. and Mingxia Zhang, 1997. "The Effects of Imperfect Competition on the Size and Distribution of Research Benefits." American Journal of Agricultural Economics. 79(4), 1252-1265.

Anderson, Lee G., 1991. "A Note on Market Power in ITQ Fisheries." Journal of Environmental Economics and Management. 21(3), 291-96.

Boyce, John R., 2004. "Instrument Choice in the Fishery." Journal of Environmental Economics and Management. 47(1), 183-206.

Brandt, Sylvia and David McEvoy, 2006. "Distributional Effects of Property Rights: Transitions in the Atlantic Herring Fishery." Marine Policy. 30(6), 659-670.

Chen, Zhigang and Rebecca Lent, 1992. "Supply Analysis in an Oligopsony Model." American Journal of Agricultural Economics. 74(4), 973-979.

Dryburgh, C.R., and C.J. Doyle, 1995. "Distribution of Research Gains under Different Market Structures: The Impact of Technological Change within the U.K. Dairy Industry." Journal of Agricultural Economics. 46(1), 80-96.

East Coast Seafood Company, 2006. www.eastcoastseafoods.com and Maine Lobsters Direct, www.mainelobstersdirect.com.

Gordon, H. Scott, 1954. "The Economic Theory of a Common Property Resource: The Fishery." Journal of Political Economy. 62(1), 124-142.

Grafton, Quinten; Kirkley, J; Squires, Dale and Quinn Weninger, 2000. A Guide to the Economic Evaluation of Individual Transferable Quota Fisheries.

Grafton, Quinten R.; Squires, Dale and Kevin J. Fox, 2000. "Private Property and Economic Efficiency: A Study of a Common-Pool Resource." Journal of Law and Economics. 43(2), 679713. 
Hamilton, Stephen F. and David L. Sunding, 1997. "The Effect of Farm Supply Shifts on Concentration and Market Power in the Food Processing Sector." American Journal of Agricultural Economics. 79(2), 524-531.

Heaps, Terry, 2003. "The Effects on Welfare of the Imposition of Individual Transferable Quotas on a Heterogeneous Fishing Fleet." Journal of Environmental Economics and Management. 46(3), 557-76.

Homans, Frances R. and James E. Wilen, 2005. "Markets and Rent Dissipation in Regulated Open Access Fisheries." Journal of Environmental Economics and Management. 49(2), 381-404.

Huang Shu-Yu and Richard J. Sexton, 1996. "Measuring Returns to an Innovation in an Imperfectly Competitive Market: Application to Mechanical Harvesting of Processing Tomatoes in Taiwan." American Journal of Agricultural Economics. 78(3), 558-571.

Love, Alan H., 1995. "Regulatory Controls and Market Power Exertion: A Study of the Pacific Halibut Industry." Natural Resource Modeling. 9(3), 229-53.

Matulich, Scott C.; Mittelhammer, Ron C. and Carlos Reberte, 1996. "Toward a More Complete Model of Individual Transferable Quotas: Implications of Incorporating the Processing Sector." Journal of Environmental Economics and Management. 31(1), 112-28.

Matulich, Scott C. and Murat Sever, 1999. "Reconsidering the Initial Allocation of ITQs: The Search for a Pareto-Safe Allocation between Fishing and Processing Sectors." Land Economics. 75(2), 203-219.

McCorriston, Steve, 2002. "Why Should Imperfect Competition Matter to Agricultural Economists?" European Review of Agricultural Economics, 29(3), 349-71.

Melnick, Rafi and Haim Shalit, 1985. "Estimating the Market for Tomatoes." American Journal of Agricultural Economics. 67(3), 573-582.

Moloney, David G. and Peter H. Pearse, 1979. "Quantitative Rights as an Instrument for Regulating Commercial Fisheries.” Journal of Fisheries Research Board Canada. 36, 859-866.

National Oceanic and Atmospheric Administration, 2006. Commercial Fisheries Statistics, http://www.st.nmfs.gov/st1/commercial/index.html.

National Research Council, 1999. Sharing the Fish: Toward a National Policy on Individual Transferable Quotas. Washington, DC: National Academy Press.

New England Fisheries Management Council (NEFMC), 1999. "Atlantic Herring Fisheries Management Plan."

New England Fisheries Management Council (NEFMC), 2004. "Herring Plan Development Team/Technical Committee Report.” May, 52004. 
New England Fisheries Management Council (NEFMC), 2005. "Draft Supplemental Environmental Impact Statement.”

New England Fisheries Management Council (NEFMC), 2006. "Final Amendment 1 to the Fishery Management Plan for Atlantic Herring."

North East Fisheries Science Center, 2003. "Stock Assessment of the Gulf of Maine - Georges Bank Atlantic Herring Complex.” Document 04-06.

Sexton, Richard J., 2000. "Industrialization and Consolidation in the US Food Sector: Implications for Competition and Welfare." American Journal of Agricultural Economics. 82(5), 1087-1104.

Sexton, Richard J. and Mingxia Zhang, 1996. "A Model of Price Determination for Fresh Produce with Application to California Iceberg Lettuce." American Journal of Agricultural Economics. 78(3), 924-934.

Squires, Dale, 2003. "Technical Efficiency in the Malaysian Gill Net Artisanal Fishery." Environment and Development Economics. 8(2), 481-504.

Terrebonne, Peter R., 1995. "Property Rights and Entrepreneurial Income in Commercial Fisheries." Journal of Environmental Economics and Management. 28(1), 68-82.

Weninger, Quinn, 2002. “Assessing Efficiency Gains from Individual Transferable Quotas: An Application to the Mid-Atlantic Surf Clam and Ocean Quahog Fishery. Fisheries Economics: Collected Essays. 2(1), 415-429.

Weninger, Quinn, 1998. “Assessing Efficiency Gains from Individual Transferable Quotas: An Application to the Mid-Atlantic Surf Clam and Ocean Quahog Fishery." American Journal of Agricultural Economics. 80(4), 750-764.

Weninger, Quinn; Grafton, Quinten R.; Kirkley, Jim and Dale Squires, 2003. "A Guide to the Economic Evaluation of Individual Transferable Quota Fisheries." Iowa State University, Department of Economics, Staff General Research Papers. 


\section{Appendix}

A.1 Proof of Proposition 1: With a perfectly competitive fishing industry and a TAC that becomes binding after the imposition of ITQs, an elastic demand $(\varepsilon>1)$ is a sufficient but not a necessary condition for an improvement in fishermen's welfare.

The proof is organized as follows. We first recall and derive useful relationships. Then we derive the expression for the change in producer surplus. The proof is then presented.

Recall that

(i) $\mathrm{z}>1$

(ii) $B_{\text {IAC }}<B_{I T Q}^{\text {unbounded }}$,

where the superscript unbounded indicates the equilibrium level of harvest under ITQ management when the TAC does not bind. Condition (ii) indicates that under scenario 4.3 the TAC is binding. In the absence of a quota, the unbounded level of harvest is determined where the new inverse supply curve $(\hat{W})$ intersects the inverse demand curve $\left((\delta / B)^{1 / \varepsilon}\right)$, i.e.,

$$
\text { (iii) } B_{\text {ITQ }}^{\text {unbounded }}=z^{\frac{\varepsilon \eta}{\varepsilon+\eta}} B_{\text {oa }} \text {. }
$$

Substituting this expression into (ii) and manipulating the inequality, we form the following useful relationship:

$$
\frac{1}{Z}\left(\frac{B_{T A C}}{B_{o a}}\right)^{\frac{(\varepsilon+\eta)}{\varepsilon \eta}}<1 .
$$

Next, consider the expression for producer surplus under perfect competition and openaccess management when the TAC is nonbinding (equation [9])

$$
P S_{o a}=W_{o a} B_{o a}-\int_{0}^{B_{o a}} W(B) d B,
$$

and the expression for producer surplus under perfect competition and ITQ management when the TAC is binding (equation [16])

$$
P S_{I T Q}=W_{T A C} B_{T A C}-\int_{0}^{B_{I A C}} \hat{W}(B) d B .
$$

When the processing sector is perfectly competitive, $W=P$, and therefore we can re-write these expressions by substituting $P_{T A C}$ in for $W_{T A C}$ and $P_{o a}$ for $W_{o a}$. When substituting the expressions for the market supply and market demand, [4a] and [4b], in the two producer surplus equations above, we get 


$$
\begin{aligned}
& P S_{\text {oa }}=\left(\delta B_{o a}^{\varepsilon-1}\right)^{1 / \varepsilon}-\frac{\eta}{1+\eta}\left(\frac{B_{o a}^{1+\eta}}{\beta}\right)^{1 / \eta}, \text { and } \\
& P S_{I T Q}=\left(\delta B_{T A C}^{\varepsilon-1}\right)^{1 / \varepsilon}-\frac{1}{z} \frac{\eta}{1+\eta}\left(\frac{B_{T A C}^{1+\eta}}{\beta}\right)^{1 / \eta}
\end{aligned}
$$

The change in producer surplus $\triangle P S=P S_{I T Q}-P S_{o a}$ can be expressed as

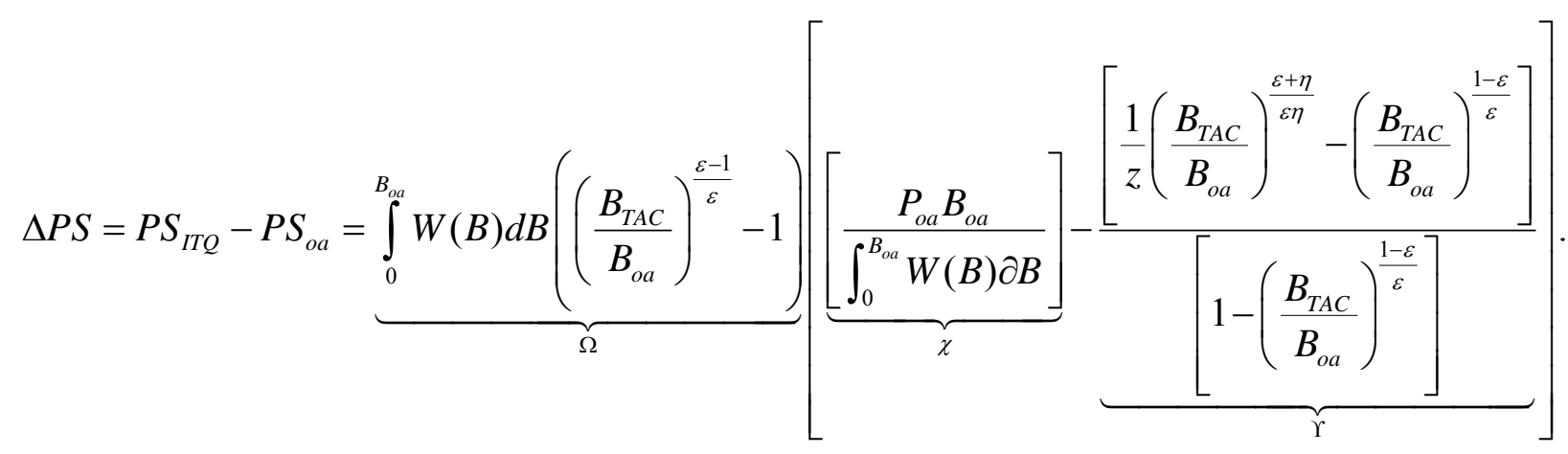

We divide the proof of the proposition into two parts. In the first part, we show that if the demand is elastic, then the change in producer surplus is positive. In the second part, we show that the change in producer surplus can be positive or negative when the demand is inelastic.

1) If the demand is elastic, then the change in producer surplus is positive.

When the demand is elastic, the first component of expression [A2], $\Omega$, is positive because, by definition, $B_{T A C}>B_{o a}$. Further, the first component within the larger brackets, $\chi$, is always greater than one because total revenue $\left(P_{o a} B_{o a}\right)$ will always exceed the area under the supply curve at the quantity $B_{o a}\left(\int_{0}^{B_{o a}} W(B) d B\right)$. Moreover, when $\varepsilon \geq 1$, the denominator of the second component in the larger brackets, $\Upsilon$, is positive and less than one. What remain to be evaluated are the sign of the numerator and the magnitude of the ratio $\Upsilon$.

The sign of the numerator of $\Upsilon$ can be either positive or negative depending on the relative magnitude of $\frac{1}{z}\left(\frac{B_{T A C}}{B_{o a}}\right)^{\frac{\varepsilon+\eta}{\varepsilon \eta}}$ and $\left(\frac{B_{T A C}}{B_{o a}}\right)^{\frac{1-\varepsilon}{\varepsilon}}$, which are both smaller than one by [A1] and by definition, respectively. In both cases (positive or negative numerator) we can show that $\triangle P S>0$. If the numerator is negative, $\Upsilon<0$, then the change in producer surplus is positive. If the numerator is positive, the ratio $\Upsilon$ is positive and we can also determine that it is less than 
one using [A1] to compare the relative magnitude of the numerator and denominator. Thus, $\chi$ $\Upsilon>0$ and the change in producer surplus is positive.

Therefore, we conclude that if $\varepsilon>1$, then $\triangle P S>0$.

2) The change in producer surplus can be positive or negative when the demand is inelastic.

When the demand is inelastic, the expression $\Omega$ in [A2] is negative. Further note that the denominator of $\Upsilon$ is negative because $\left(\frac{B_{T A C}}{B_{o a}}\right)^{\frac{1-\varepsilon}{\varepsilon}}>1$. Moreover, from [A1] we know that the first component in the numerator of $\Upsilon, \frac{1}{Z}\left(\frac{B_{T A C}}{B_{o a}}\right)^{\frac{\varepsilon+\eta}{\varepsilon \eta}}$, is less than 1. Consequently, the numerator of $\Upsilon$ is also negative. Thus, with inelastic demand, both $\chi$ and $\Upsilon$ are positive and fishermen will lose surplus from ITQ management if $\chi>\Upsilon$, and will gain surplus if $\chi<\Upsilon$.

\section{A.2 Demonstration of Lemma 1}

When the demand is inelastic, the sign of $\triangle P S$ is undetermined. Taking the first derivative of $\triangle P S$ in [A2] with respect to $z$ yields

$$
\frac{\partial \Delta P S}{\partial z}=-\Omega \cdot \frac{\partial \Upsilon}{\partial z}=\Omega \cdot \frac{\frac{1}{z^{2}}\left(\frac{B_{T A C}}{B_{o a}}\right)^{\frac{\varepsilon+\eta}{\varepsilon \eta}}}{1-\left(\frac{B_{T A C}}{B_{o a}}\right)^{\frac{1-\varepsilon}{\varepsilon}}}>0 .
$$

The marginal effect of $z$ on the change in producer surplus is positive because under an inelastic demand both $\Omega$ and the denominator of $\Upsilon$ are negative. This result implies that an increase in efficiency gain leads to an increase in $\triangle P S$. Thus, the implementation of ITQ will result in an increase (decrease) in producer surplus when the efficiency gains are sufficiently large (small). 
A.3 Proof of Proposition 2: When the processing sector is imperfectly competitive and the TAC becomes binding after ITQ management, $\lambda<\eta /(\eta+1)$ is a sufficient but not a necessary condition for an improvement in fishermen's welfare.

Subtract equation [12] from equation [9] and substitute the expressions for $\int_{0}^{B_{\text {TaC }}} \hat{W}(B) d B$ and $\int_{0}^{B_{\text {ioa }}} W(B) d B$ to obtain:

$\Delta P S=\left[\lambda \hat{W}\left(B_{i T A C}\right)+(1-\lambda) P\left(B_{\text {iTAC }}\right)\right] B_{\text {iTAC }}-\frac{1}{z} \frac{\eta}{1+\eta}\left(\frac{B_{\text {iTAC }}^{1+\eta}}{\beta}\right)^{1 / \eta}-W\left(B_{\text {ioa }}\right) B_{\text {ioa }}+\frac{\eta}{1+\eta}\left(\frac{B_{\text {ioa }}^{1+\eta}}{\beta}\right)^{1 / \eta}$.

Using $\hat{W}=(1 / z)\left(B_{\text {iTAC }} / \beta\right)^{1 / \eta}, W=\left(B_{\text {ioa }} / \beta\right)^{1 / \eta}$, and rearranging terms, we can rearrange this expression to form

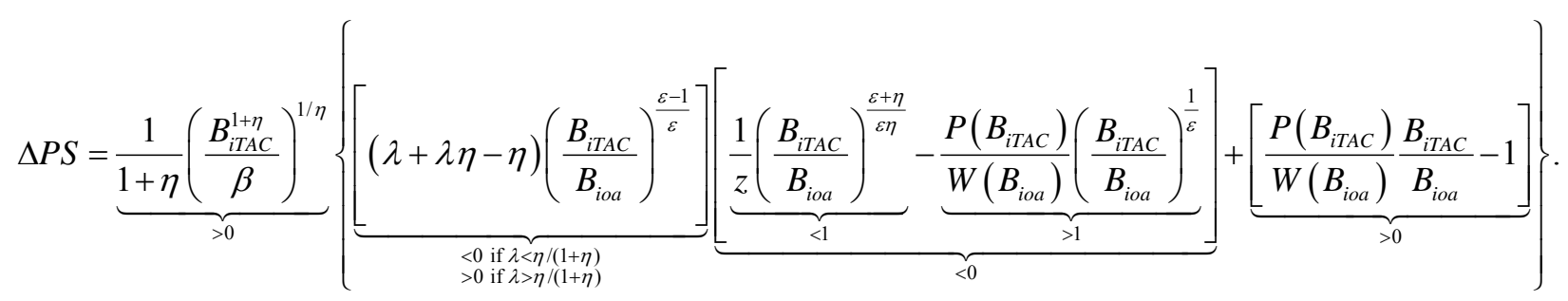

This expression and the signs of its various elements show the following:

1) If $\lambda<\eta /(1+\eta)$, then the change in producer surplus from the change in management is positive.

2) If $\lambda>\eta /(\eta+1)$, then the change in producer surplus is positive (negative) if the sum of the two elements inside the curly bracket is positive (negative).

\section{A.4 Demonstration of Lemma 2}

When $\lambda>\eta /(\eta+1)$ the sign of $\triangle P S$ is undetermined. Taking the first derivative of $\triangle P S$ with respect to $z$ yields

$\frac{\partial \Delta P S}{\partial z}=-[\underbrace{\frac{1}{(1+\eta)}\left(\frac{B_{\text {ioo }}^{1+\eta}}{\beta}\right)^{1 / \eta}}_{>0} \underbrace{(\lambda+\lambda \eta-\eta)}_{>0} \underbrace{\left(\frac{B_{\text {iTAC }}}{B_{\text {ioo }}}\right)^{\frac{\varepsilon-1}{\varepsilon}}\left(\frac{B_{\text {iTAC }}}{B_{\text {ioa }}}\right)^{\frac{\varepsilon+\eta}{\varepsilon \eta}} \frac{1}{z^{2}}}_{>0}]<0$,

indicating that the change in producer surplus from ITQ management is decreasing with larger efficiency gains. 
Table 1. Percentage of TAC mt by management area for 2000 - 2004 (vessel trip reports)

\begin{tabular}{cccccc}
\hline Year & Area 1A & Area 1B & Area 2 & Area 3 & Total (mt) \\
\hline & $\begin{array}{c}\mathrm{TAC}=60,000 \mathrm{mt} \\
\text { \% of TAC }\end{array}$ & $\begin{array}{c}\mathrm{TAC}=10,000 \mathrm{mt} \\
\% \text { of TAC }\end{array}$ & $\begin{array}{c}\mathrm{TAC}=50,000 \mathrm{mt} \\
\% \text { of TAC }\end{array}$ & $\begin{array}{c}\text { TAC }=60,000 \mathrm{mt} \\
\% \text { of } \mathrm{TAC}\end{array}$ & $\mathbf{1 8 0 , 0 0 0 ~ m t}$ \\
$\mathbf{2 0 0 0}$ & $101 \%$ & $75 \%$ & $54 \%$ & $26 \%$ & $\mathbf{1 0 8 , 6 5 8}$ \\
$\mathbf{2 0 0 1}$ & $89 \%$ & $167 \%$ & $32 \%$ & $70 \%$ & $\mathbf{1 2 1 , 3 3 2}$ \\
$\mathbf{2 0 0 2}$ & $100 \%$ & $73 \%$ & $22 \%$ & $28 \%$ & $\mathbf{9 2 , 5 9 4}$ \\
$\mathbf{2 0 0 3}$ & $100 \%$ & $50 \%$ & $33 \%$ & $36 \%$ & $\mathbf{1 0 3 , 1 8 7}$ \\
$\mathbf{2 0 0 4}$ & $100 \%$ & $136 \%$ & $23 \%$ & $15 \%$ & $\mathbf{9 4 , 1 5 2}$ \\
\hline
\end{tabular}

* The TAC in Area 3 was increased from 50,000 mt to 60,000 mt in 2003

Sources: NEFMC 2005 and NEFMC 2006. 
Table 2. Volume and percentage of herring sold to bait dealers for the largest four bait dealers in 2003

\begin{tabular}{cc}
\hline $\begin{array}{c}\text { Volume of Largest 4 } \\
\text { Bait Dealers }\end{array}$ & $\begin{array}{c}\text { Cumulative Percentage of } \\
\text { Total Bait Harvest }\end{array}$ \\
\hline $11,793 \mathrm{mt}$ & $20 \%$ \\
$8,332 \mathrm{mt}$ & $34 \%$ \\
$7,451 \mathrm{mt}$ & $47 \%$ \\
$5,443 \mathrm{mt}$ & $56 \%$ \\
\hline Source: Computed using 2003 Dealer Data and NEFMC (2006)
\end{tabular}


Table 3. Predicted directional change in fishermen's welfare due to ITQ management

\begin{tabular}{|c|c|c|c|c|}
\hline \multirow[t]{2}{*}{ Scenario } & \multirow{2}{*}{$\begin{array}{c}\text { Relevant } \\
\text { Management } \\
\text { Area } \\
\end{array}$} & \multicolumn{2}{|c|}{ Perfect competition } & Imperfect competition \\
\hline & & $\varepsilon>1$ & $\varepsilon<1$ & $\varepsilon<1$ \\
\hline $\begin{array}{l}\text { 4.1 Nonbinding TAC } \\
\text { (Open-Access and ITQs) }\end{array}$ & 2 and 3 & + & - & - \\
\hline $\begin{array}{l}\text { 4.2 Binding TAC } \\
\text { (Open-Access and ITQs) }\end{array}$ & $1 \mathrm{~A}$ and $1 \mathrm{~B}$ & + & + & $\begin{array}{l}(+) \text { if } \lambda<\eta /(\eta+1) \\
(-) \text { if } \lambda>\eta /(\eta+1)\end{array}$ \\
\hline $\begin{array}{l}\text { 4.3 Nonbinding TAC with } \\
\text { Open-Access/ } \\
\text { Binding TAC with ITQs }\end{array}$ & $1 \mathrm{~B}$ & + & $\begin{array}{c}+(-) \text { if } z \text { is } \\
\text { sufficiently } \\
\text { large (small) }\end{array}$ & $\begin{array}{c}\text { (+) if } \lambda<\eta /(\eta+1) \\
(+) \text { if } \lambda>\eta /(\eta+1) \text { and } z \text { is } \\
\text { sufficiently small } \\
(-) \text { if } \lambda>\eta /(\eta+1) \text { and } z \text { is } \\
\text { sufficiently large }\end{array}$ \\
\hline
\end{tabular}


Figure 1. Management areas in the Atlantic herring fishery

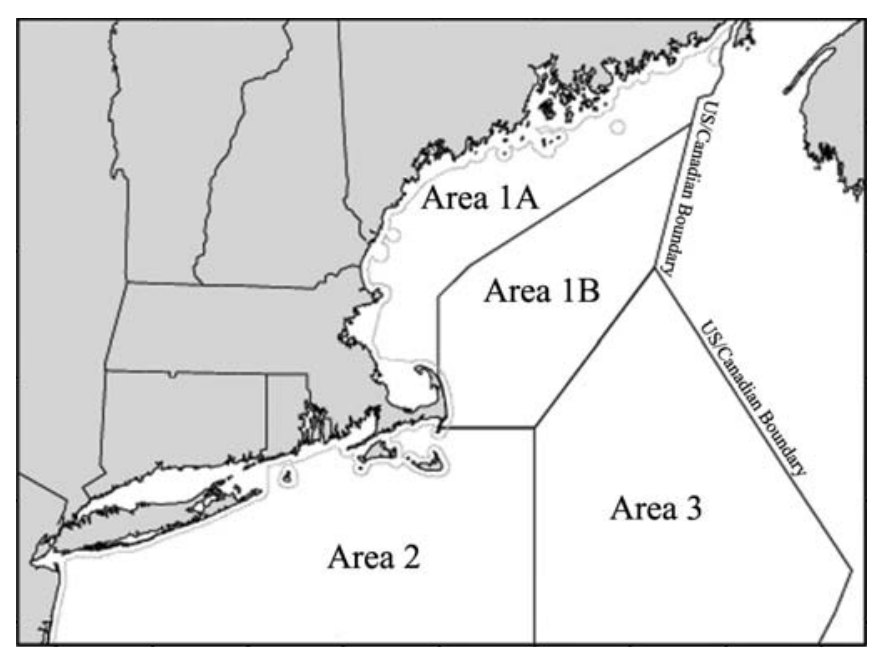

Source: Adapted from original map included in NEFMC 2005 


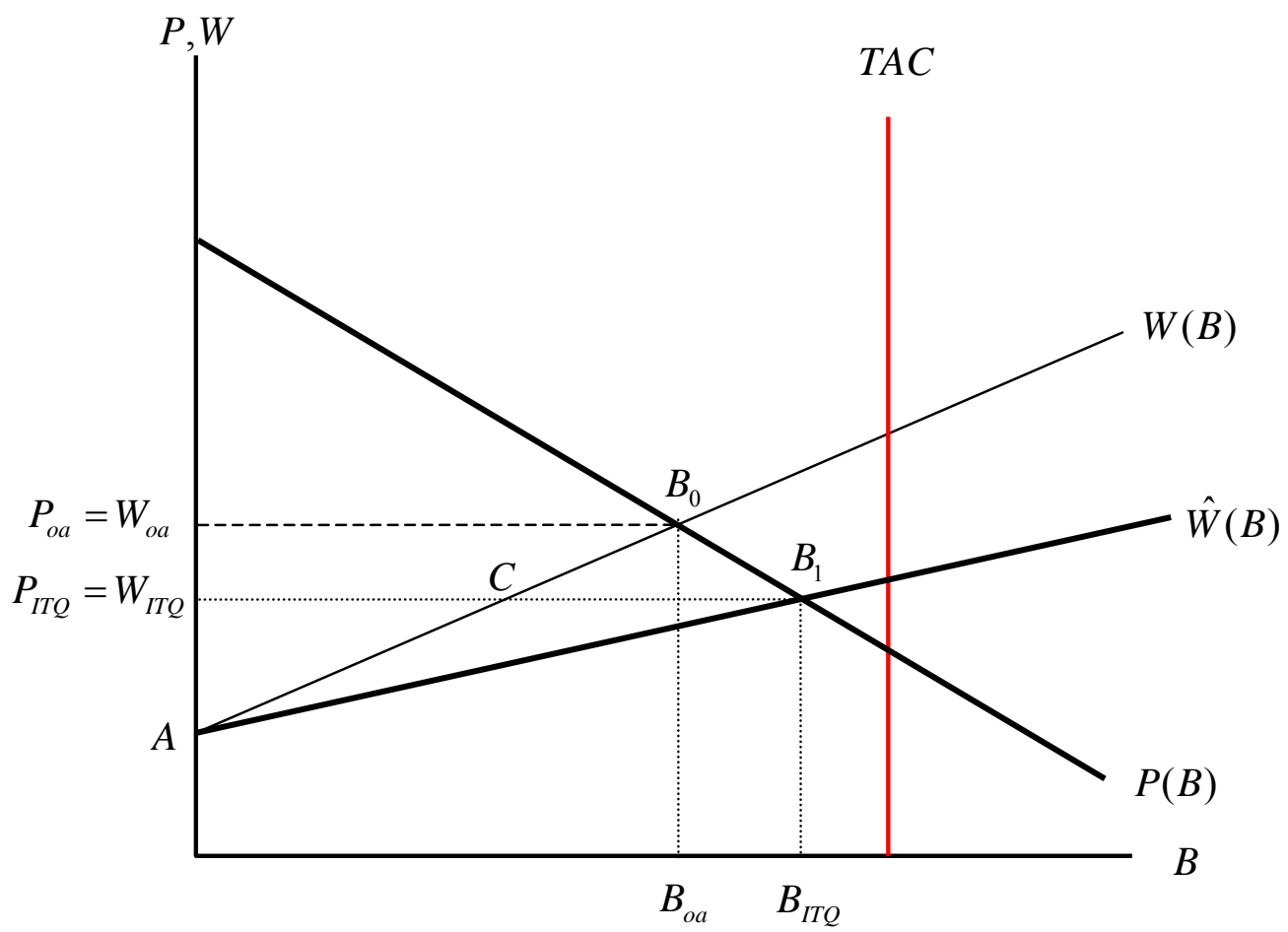

Figure 2. Changes in producer surplus from ITQ management under perfect competition with a nonbinding TAC 


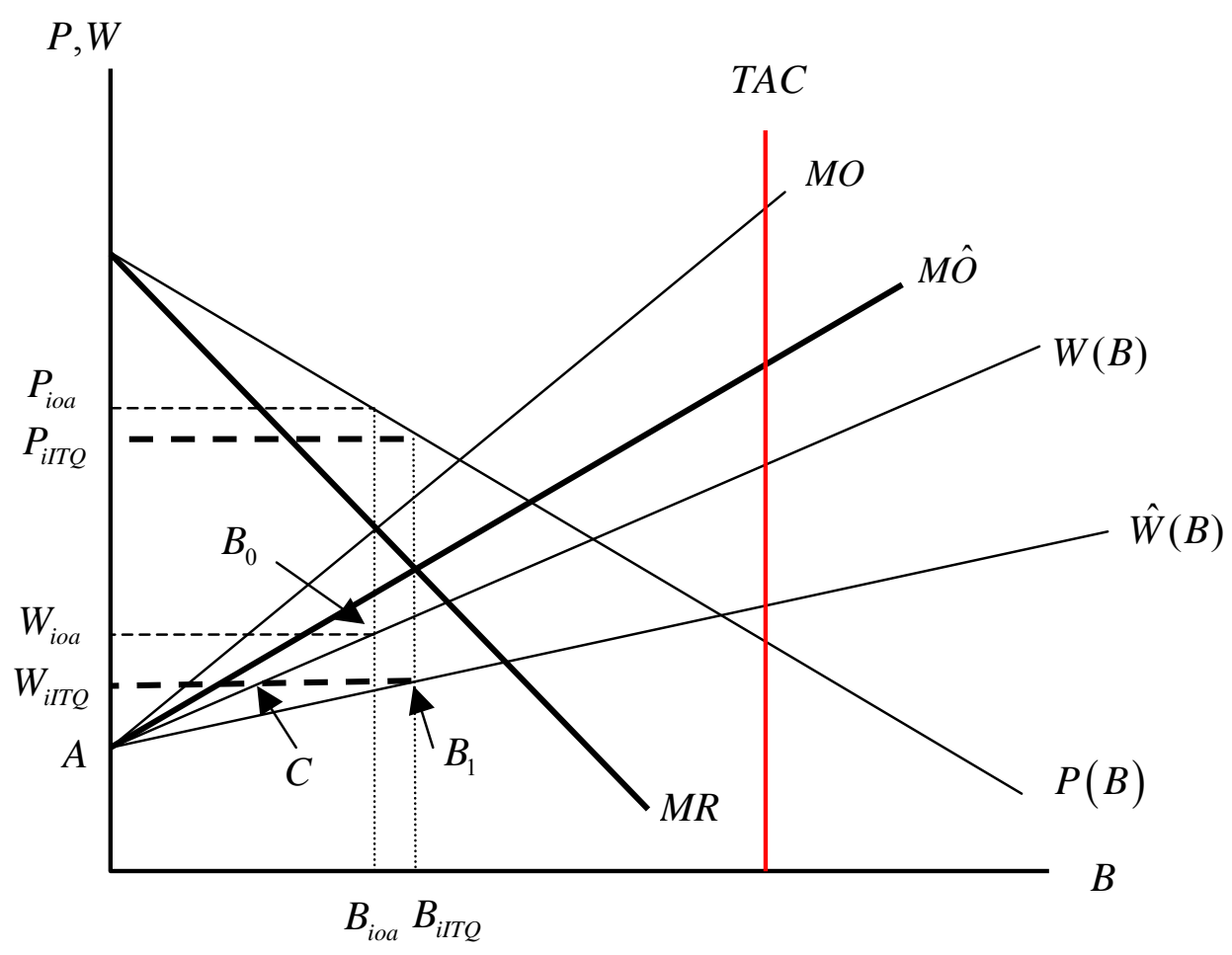

Figure 3. Changes in producer surplus when transitioning from open-access to ITQ management under imperfect competition with a nonbinding TAC

Note:

$$
\begin{aligned}
& M R=\lambda\left[P^{\prime}(B) B+P(B)\right]+(1-\lambda) P(B) \\
& M O=\theta\left[W^{\prime}(B) B+W(B)\right]+(1-\theta) W(B) \\
& M \hat{O}=\theta\left[\hat{W}^{\prime}(B) B+\hat{W}(B)\right]+(1-\theta) \hat{W}(B)
\end{aligned}
$$




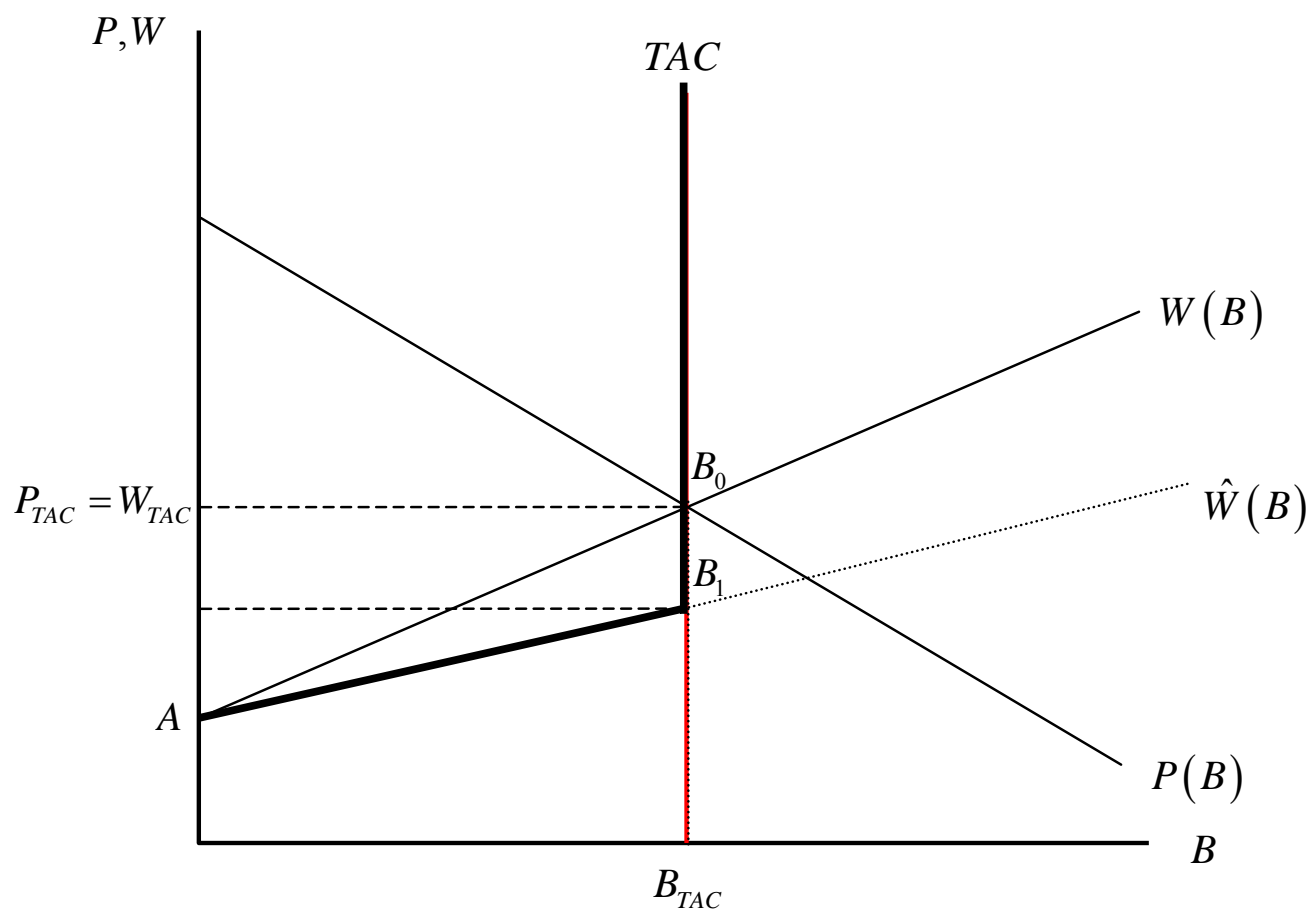

Figure 4. Changes in producer surplus when transitioning from open-access to ITQ management under perfect competition with a binding TAC 


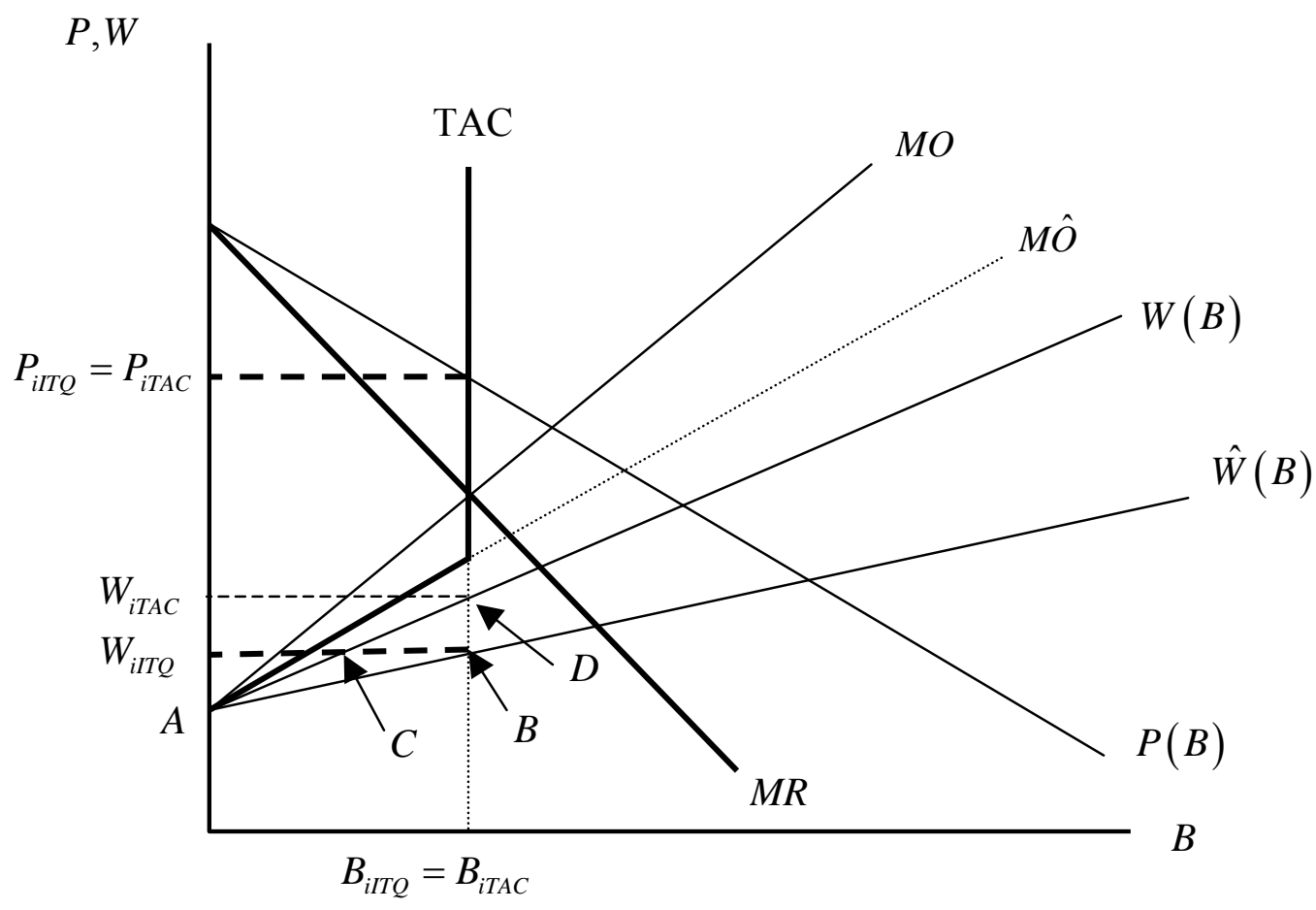

Figure 5. Changes in producer surplus when transitioning from open-access to ITQ management under imperfect competition with a binding TAC 


\section{Endnotes}

\footnotetext{
${ }^{\mathrm{i}}$ Formally, the fishery is managed in state waters by the ASMFC and in federal waters by the NEFMC. Both management bodies have developed separate but largely consistent management plans. A critical difference between the two is the additional "days out" provision in the ASMFC's Interstate FMP.

ii The individual quota regulation proposed within Amendment 1 is defined as an individual fishing quota (IFQ) system. Typically, IFQs describe a quota regime in which quotas may not be traded among participants. However, the IFQs proposed by Atlantic herring management allow for trading and therefore, in this paper, we describe the regulation as an ITQ system.

iii For a complete assessment, see North East Fisheries Science Center (2003).

${ }^{\text {iv }}$ Brandt and McEvoy (2006) find significant levels of excess capacity among Atlantic herring fishermen.

${ }^{v}$ The wholesalers process and sell herring as bait in a number of ways. A portion of herring is sold fresh to lobster fishermen who purchase bait directly from the wholesaler. While fresh herring will only last a few days, salted bait can last up to six months. The salting process includes rinsing, layering herring in salt, barreling and then shipping by boat or truck.

${ }^{\text {vi }}$ The $56 \%$ estimate should be considered a conservative lower bound. Some dealers have bait holdings listed under different permit numbers and the available data is not detailed enough to properly match multiple permits to single firms.

${ }^{\text {vii }}$ Recall, raw herring is sold either unaltered as fresh bait or sold salted and barreled. For this analysis, we assume all finished bait is homogeneous and the cost component in the profit function captures all relevant processing costs.

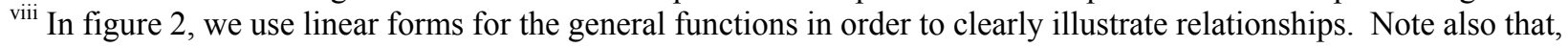
the equilibrium expression in [8] can be alternatively written as $\theta M R(Q)+(1-\theta) P(Q)-c=\lambda M C(B)+(1-\lambda) W(B)$ where $M R(Q)=\partial[P(Q) Q] / \partial Q$ is the industry marginal revenue schedule and $M C(B)=\partial[W(B) B] / \partial B$ is the industry marginal cost schedule. Because $\theta(\lambda)$ takes values between zero (i.e., perfect competition) and one (i.e., monopoly), it can be interpreted as a weight measuring the importance of the demand curve (supply curve) relative to the marginal revenue (marginal outlay) curve in determining the equilibrium quantity of bait (Melnick and Shalit 1985). The alternative expression for equation [8] is useful in the illustration of equilibrium under imperfect competition.

${ }^{\text {ix }}$ It is useful to note that because we model the long-term effect of an ITQ system as an outward pivot in the market supply curve, lobstermen will necessarily benefit from the management change in this scenario.

${ }^{x}$ It may be reasonable to assume that the reduction in fishing costs, and therefore the magnitude of the pivot in supply, will differ according to the characteristics of the four fishing areas. However, because we are estimating changes in welfare within isolated fishing areas there is no need to differentiate supply shifts for the different areas in our analysis.
} 